\title{
Associations Between Physical Activity and the Androgenic/Estrogenic Status of Men
}

\author{
M. SLOWINSKA-LISOWSKA ${ }^{1}$, P. JOZKOW ${ }^{1}$, M. MEDRAS ${ }^{1,2}$ \\ ${ }^{1}$ Department of Sports Medicine, University School of Physical Education, Wrocław, Poland, \\ ${ }^{2}$ Department of Endocrinology, Diabetology and Isotope Treatment, Wrocław Medical University, \\ Wrocław, Poland
}

Received July 1, 2009

Accepted December 3, 2009

On-line April 20, 2010

\section{Summary}

Concentrations of numerous hormones decrease with age. Some authors imply that a syndrome of partial endocrine deficiency may occur in the aging men. Among many lifestyle factors that influence hormonal status is physical activity. Especially interesting are relations between physical activity and the androgenic/estrogenic status of men. The aim of this study was to evaluate age-related changes of serum androgens, estradiol and SHBG in men presenting different levels of physical activity. Hormonal parameters were measured in a cohort of 387 healthy Caucasian men (aged from 24 to 72 years) from one administrative region of Poland. Their level of physical activity was determined by means of the International Physical Activity Questionnaire (IPAQ). We have found that contrary to SHBG concentration, total testosterone, free testosterone, bioavailable testosterone, calculated free testosterone and estradiol were negatively associated with age in the investigated subjects. Apart from estradiol, physical activity did not influence concentrations of the studied parameters. In younger (24-48 years), physically active males estradiol was significantly higher than in subjects characterized by a low level of physical activity. The situation was opposite in older males (48-72 years). In this age group low level of physical activity was associated with lower concentration of estradiol. Undertaking physical effort increased the decline of estradiol level with age.

\section{Key words}

Hormones • Age • Motor activity • Lifestyle

\section{Corresponding author}

Malgorzata Slowinska-Lisowska, Department of Sports Medicine, University School of Physical Education, ul. Paderewskiego 35, 51-617 Wrocław, Poland. E-mail: slowik29@gmail.com

\section{Introduction}

Concentrations of numerous hormones decrease with age. This phenomenon has an individual dynamics and depends on genetic, psychical and social factors (stress, depressive states). It is also influenced by lifestyle: tobacco smoking, alcohol drinking and physical activity (Field et al. 1994, Svartberg and Jorde 2007, Shiels et al. 2009, Wolin et al. 2007, Muller et al. 2003).

The influence of repeated physical efforts on the androgenic status of aging men is not fully explored. Testosterone deficiency is supposed to be associated with vanishing of the muscle mass, increase of the visceral fat, insulin resistance, arterial hypertension, dyslipidemia as well as osteopenia (Denti et al. 2000, Vanderschueren and Vandenput 2000).

Estrogens warrant proper function of the reproductive, skeletal and nervous systems in men. Although it is assumed that male aging is accompanied by a gradual increase of estrogens, not all authors confirm this observation. The data on associations between estrogens and physical activity are scarce (Drafta et al. 1982, Shiels et al. 2009). We wanted to evaluate the impact of physical activity on age-related trends in hormonal status of men living in the Lower Silesia Region.

\section{Materials and Methods}

Our investigation is a part of a larger project named Health of Adults in Lower Silesia (HALS). The region of Lower Silesia is located in southern Poland and 
Table 1. Basic data of the study group.

\begin{tabular}{llll}
\hline Parameter & $\begin{array}{l}\text { All } \\
(\mathrm{n}=387)\end{array}$ & $\begin{array}{l}\text { High activity } \\
(\mathrm{n}=191)\end{array}$ & $\begin{array}{l}\text { Low activity } \\
(\mathrm{n}=196)\end{array}$ \\
\hline Age (years) & $48.3 \pm 14.6$ & $47.1 \pm 14.3$ & $49.5 \pm 14.6$ \\
Weight $(\mathrm{kg})$ & $84.9 \pm 13.4$ & $85.3 \pm 13.5$ & $84.7 \pm 13.4$ \\
Height $(\mathrm{cm})$ & $175.0 \pm 6.9$ & $176.0 \pm 6.5$ & $175.6 \pm 6.8$ \\
Body mass index $\left(\mathrm{kg} / \mathrm{m}^{2}\right)$ & $27.5 \pm 4.1$ & $27.3 \pm 4.1$ & $27.6 \pm 4.2$ \\
\hline
\end{tabular}

Data are mean $\pm \mathrm{SD}$.

Table 2. Basic of the study group.

\begin{tabular}{llllll}
\hline Age (years) & $\begin{array}{l}\mathbf{2 4 - 3 0} \\
\mathrm{n}=91\end{array}$ & $\begin{array}{l}\mathbf{3 1 - 4 0} \\
\mathrm{n}=68\end{array}$ & $\begin{array}{l}\mathbf{4 1 - 5 0} \\
\mathrm{n}=96\end{array}$ & $\begin{array}{l}\mathbf{5 1} \mathbf{- 6 0} \\
\mathrm{n}=98\end{array}$ & $\begin{array}{l}\mathbf{6 1} \mathbf{- 7 2} \\
\mathrm{n}=34\end{array}$ \\
\hline Weight $(\mathrm{kg})]$ & $81.8 \pm 12.5$ & $85.7 \pm 13.1$ & $87.0 \pm 13.8$ & $85.8 \pm 15.1$ & $81.9 \pm 11.7$ \\
$\begin{array}{l}\text { Height }(\mathrm{cm}) \\
\text { Body mass index }\left(\mathrm{kg} / \mathrm{m}^{2}\right)\end{array}$ & $25.4 \pm 3.4$ & $27.1 \pm 3.8$ & $28.1 \pm 4.0$ & $28.9 \pm 4.8$ & $27.5 \pm 3.3$ \\
\hline
\end{tabular}

Data are mean \pm SD.

covers an area of $19947 \mathrm{~km}^{2}$. It has 2880000 inhabitants (100\% Caucasian). The project of the study was approved by the Bioethics Committee at the University School of Physical Education, Wroclaw, Poland.

We sent invitations to participate in the investigation to 900 adult men living in Lower Silesia. They were randomly selected by the Local Data Bank (Regional Statistical Office). As an operator the personal identification number was used. From the target group, 372 subjects (43\%) submitted their written consents and were enrolled for the study.

The subjects aged from 24 to 72 years. They underwent a standard medical interview and a full physical examination. About $43 \%$ of subjects had university degree. According to the medical interviews $21 \%$ had arterial hypertension, $19 \%$ chronic low back pain, $5 \%$ benign prostate hyperplasia and $4 \%$ diabetes. The anthropological characteristics of the studied men are shown in Tables 1 and 2. Subjects distinguished upon the level of physical activity did not differ as to age, height, weight and body mass index (BMI).

Physical activity of the studied subjects was determined by means of the Polish version of the International Physical Activity Questionnaire (IPAQ, short form, last 7-day recall). IPAQ is commonly used as a comparable and standardized self-report measure of habitual physical activity of populations from different sociocultural contexts. It has been validated in healthy adults from 12 countries (Craig et al. 2003). The questionnaire was also compared against doubly labeled water what implicated that it may underestimate energy expenditure at higher levels of physical activity (Maddison et al. 2007). In the continuous scale the amount of physical exercise was counted as multiples of resting metabolic rate by minutes of performance during a week (METs-minute/week). In our study group we adapted the criteria presented by the IPAQ scientific committee [http://www.ipaq.ki.se/]. According to above classification persons who moved at least 12500 steps a day or the equivalent in moderate or vigorous activities were highly active. They had at least an hour more moderate-intensity activity over and above the basal level of activity or half an hour of vigorous-intensity activity over and above basal levels daily (basal is 5000 steps/day). Subjects who did not fulfill above criteria were assigned to the subgroup of low physical activity.

\section{Hormone measurements}

Radioimmunoassay kits were used for measurements of total testosterone (TT), free testosterone and estradiol (Diagnostic Products Corporation, USA). The intra- and interassay coefficients of variation (CV) were $5.5 \%$ and $5.9 \%$ for total testosterone, $3.2 \%$ and $8.5 \%$ for free testosterone, $3.1 \%$ and $4.5 \%$ for estradiol. 
Table 3. Multiple regression models for estradiol, total testosterone, bioavailabe testosterone, SHBG, free testosterone and calculated free testosterone with statistically significant regresses.

\begin{tabular}{|c|c|c|c|c|c|c|c|c|c|}
\hline \multirow{2}{*}{$\begin{array}{l}\text { Parameters } \\
\text { Independent variables }\end{array}$} & \multicolumn{3}{|c|}{ Estradiol } & \multicolumn{3}{|c|}{ Total testosterone } & \multicolumn{3}{|c|}{ Bioavailable testosterone } \\
\hline & $\mathrm{B}$ & $\mathrm{SE}$ & $\mathrm{P}<$ & $\mathrm{B}$ & SE & $\mathrm{P}<$ & B & SE & $\mathrm{P}<$ \\
\hline Intercept & 83.36 & 5.68 & 0.0001 & 21.80 & 1.13 & 0.0001 & 12.66 & 0.95 & 0.0001 \\
\hline Age & -0.52 & 0.12 & 0.001 & -0.10 & 0.023 & 0.001 & -0.093 & 0.019 & 0.001 \\
\hline Low physical activity and age & -0.5 & 0.16 & 0.0002 & NS & NS & NS & NS & NS & NS \\
\hline Adjusted $R^{2}$ & \multicolumn{3}{|c|}{0.21} & \multicolumn{3}{|c|}{0.28} & \multicolumn{3}{|c|}{0.23} \\
\hline$P<$ & \multicolumn{3}{|c|}{0.0001} & \multicolumn{3}{|c|}{0.0001} & \multicolumn{3}{|c|}{0.001} \\
\hline Parameters & \multicolumn{3}{|c|}{ SHBG } & \multicolumn{3}{|c|}{ Free Testosterone } & \multicolumn{3}{|c|}{$\begin{array}{c}\text { Calculated Free } \\
\text { Testosterone }\end{array}$} \\
\hline Independent variables & $\mathrm{B}$ & SE & $\mathrm{P}<$ & B & SE & $\mathrm{P}<$ & B & SE & $\mathrm{P}<$ \\
\hline Intercept & 25.16 & 3.02 & 0.0001 & 73.51 & 4.37 & 0.001 & 0.54 & 0.04 & 0.0001 \\
\hline Age & 0.25 & 0.19 & 0.001 & -0.62 & 0.06 & 0.001 & -0.004 & 0.0082 & 0.0001 \\
\hline Low physical activity and age & NS & NS & NS & NS & NS & NS & NS & NS & NS \\
\hline Adjusted $R^{2}$ & & 0.19 & & & 0.16 & & & 0.23 & \\
\hline$P<$ & & 0.001 & & & 0.001 & & & 0.001 & \\
\hline
\end{tabular}

B - regression coefficient, SE - standard error

SHBG was measured using immunoradiometric assayIRMA kits (Immunotech, Czech Republic). The intraand interassay $\mathrm{CV}$ were 3.8 and $7.0 \%$.

The concentrations of bioavailable testosterone and calculated free testosterone were assessed with a calculator developed at the Hormonology Department, University Hospital of Ghent, Belgium (details on the calculation are available on the website: http://www.issam.ch/freetesto.htm).

\section{Statistical methods}

Models evaluating concentrations of hormones in groups of different physical activity levels and age were built using least squares multiple linear ridge stepwise regression. The statistical significance of models was tested by F-test from one-way ANOVA. The statistical significance of variables was tested using Student t-test. Non-significant variables in the models were eliminated by forward selection. All calculations were performed using statistical package Statistica v.6 (Statsoft Inc.).

\section{Results}

The multiple regression models for hormonal levels with statistically significant regresses are shown in
Table 3. Diagrams of spread and the regression straight line of the concentrations of investigated hormones with age are shown in Figures 1-6.

We have found that concentrations of total testosterone, free testosterone, bioavailable testosterone, calculated free testosterone, SHBG and estradiol were significantly influenced by age. Physical activity did not modify concentrations of androgens in the investigated men. The mean estradiol level in men aged 24-48 years was higher in the subgroup declaring high level of physical activity. Contrary to above, in men $>48$ years. estradiol was lower in those who were physically active. It is worth to notice that estradiol decreased by approximately $5.2 \mathrm{nmol} / \mathrm{l}$ per 10 years in highly active men. In subjects, who declared low level of physical activity, this decrease was insignificant $(0.2 \mathrm{nmol} / 1 \mathrm{per}$ 10 years).

\section{Discussion}

Previous studies of the Polish population suggested a rather high incidence of sedentary lifestyle and a relatively low level of occupational physical activity (Kaleta et al. 2007). In contrast, in our study about $50 \%$ of men declared high level of daily physical activity. Similar outcomes were reported by authors who 
showed that the amount of physical activity was higher when IPAQ questionnaires were filled by subjects themselves rather than by experienced interviewers (Biernat et al. 2008). We have to mention a suggestion that IPAQ may overestimate the level of physical activity (Rzewnicki et al. 2003). On the other hand, it is probable that the investigated men were more health-conscious

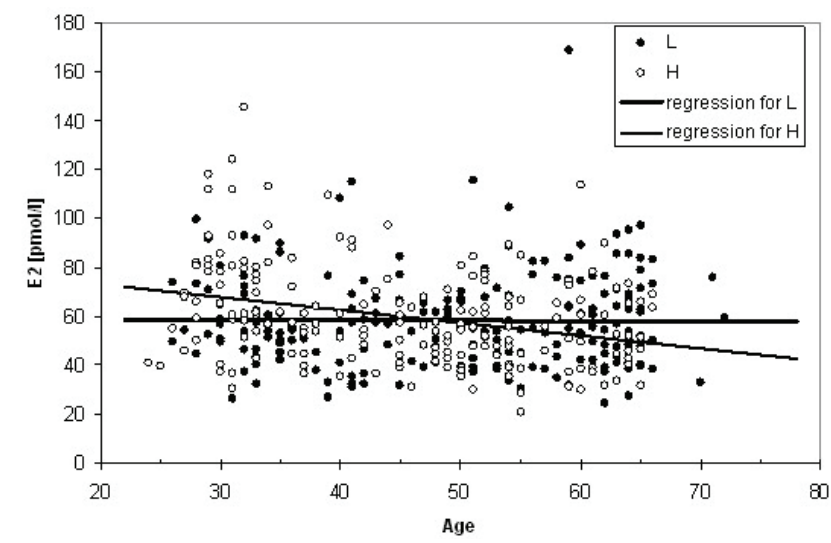

Fig. 1. Concentration of estradiol by age for men with low (L) and high $(\mathrm{H})$ physical activity.

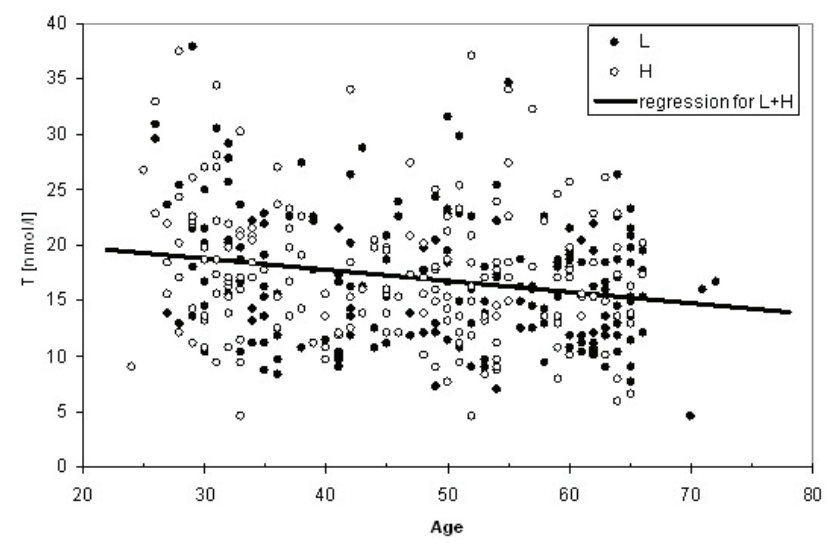

Fig. 2. Concentration of total testosterone by age for men with low $(\mathrm{L})$ and high $(\mathrm{H})$ physical activity.

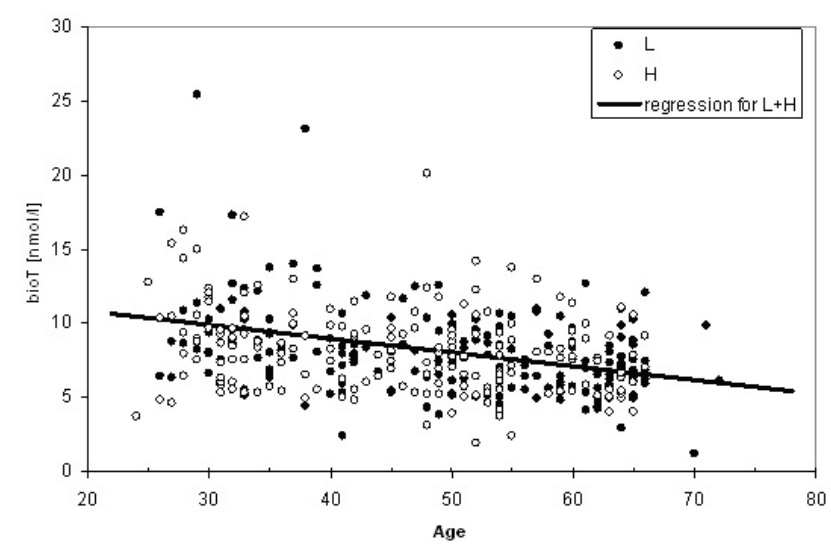

Fig. 3. Concentration of bioavailable testosterone by age for men with low $(\mathrm{L})$ and high $(\mathrm{H})$ physical activity. than the average.

Our results are consistent with observations pointing to a decreased production of androgens and increased serum concentration of sex hormone binding globulin in aging men (Gray et al. 1991, Kaufman and Vermeulen 2005, Van den Beld et al. 1999).

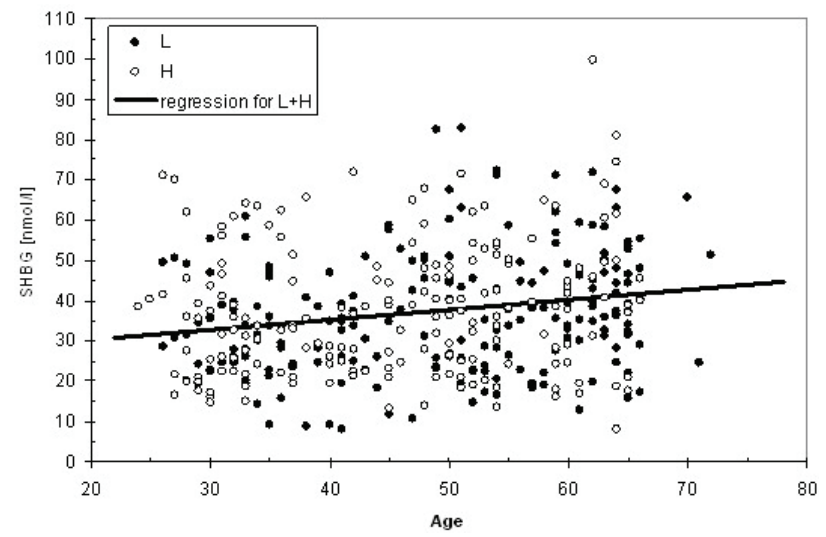

Fig. 4. Concentration of SHBG by age for men with low (L) and high $(\mathrm{H})$ physical activity.

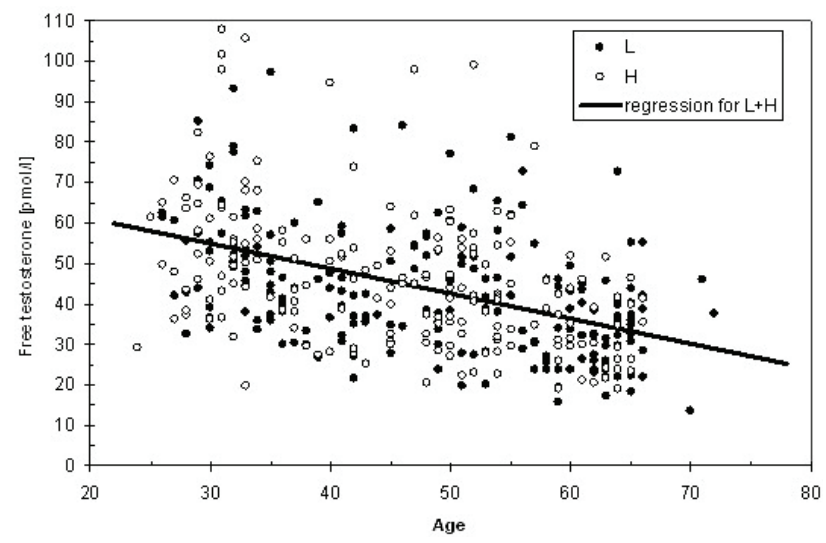

Fig. 5. Concentration of free testosterone by age for men with low $(\mathrm{L})$ and high $(\mathrm{H})$ physical activity.

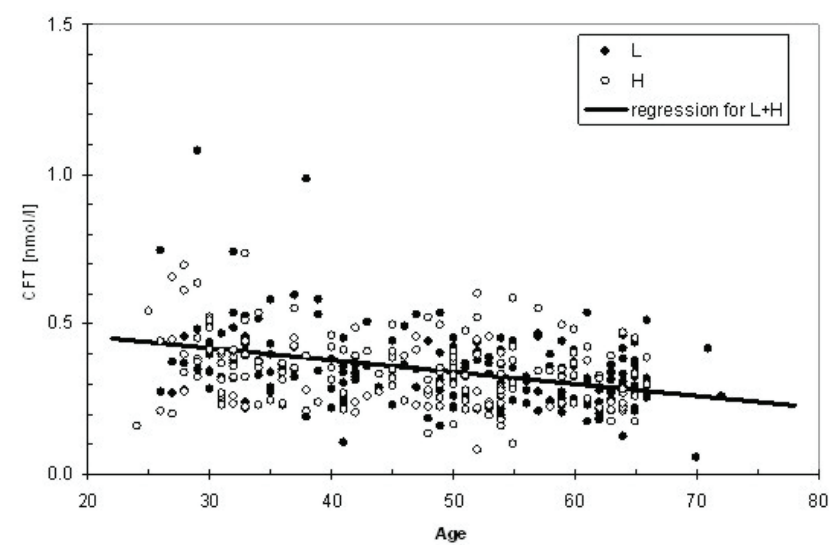

Fig. 6. Concentration of calculated free testosterone by age for men with low $(\mathrm{L})$ and high $(\mathrm{H})$ physical activity. 
Influence of age on estradiol concentration is not so clear. Several studies found that the level of total estradiol does not change with age in men (Ferrini and Barret-Connor 1998, Muller et al. 2003). Others observed a decrease of estradiol only in the old age (Van den Beld et al. 2000). However, in a cross-sectional study of men aged 25-85 years, bioavailable estradiol decreased significantly with age (Khosla et al. 1998). Associations between estradiol levels and ER $\alpha$ polymorphisms were suggestive for estrogen-related processes, possibly related to changes in the neuroendocrine regulation of testosterone production in elderly men (Lapauw et al. 2008).

In our investigation estradiol was negatively associated with age and its concentration was influenced by physical activity. We have noticed that in men between 24-48 years the estradiol concentration was higher in physically active rather than inactive subjects. At 48 years the mean estradiol concentration was similar in both groups. In men older than 48 years physically active subjects had lower concentration of estradiol.

The age-dependent decline of estradiol was apparent in physically active men. The decrease of estradiol in inactive subjects was statistically insignificant. One may suspect that exercise exacerbates estradiol reduction with age.

It was noticed previously that vigorous physical activity undertaken more than four times per week increased total estradiol concentration more than less frequent vigorous exercise. According to Shiels et al. (2009) such results question the opinion that those, who engage in vigorous physical activity, tend to have lower body fat, and thus should have lower estradiol production by adipocytes given the same testosterone level.

We have no explanation for a steeper estradiol decline with age in active subjects and a higher concentration of estradiol in young, physically active men. We underline the fact that there were no differences in body weight and BMI between subgroups distinguished upon physical activity level. This finding can be a result of differences in the aromatase activity, as the physiological balance between sex steroid hormones is largely controlled by the aromatase cytochrome P-450 (Conley and Hinshelwood 2001).

Studies performed in rats proved that single-time physical effort evokes an increase of the skeletal muscle aromatase cytochrome P-450 activity in male animals. On the contrary, a decrease of the aromatase activity was observed in female rats subjected to the same stimulation.
After an intensive effort, the estradiol concentration increased in tissues obtained from the male rats, whereas the testosterone concentration increased in the female subjects (Aizawa et al. 2008).

Associations between physical activity and concentrations of androgens are not fully elucidated. In our sample physical activity did not modify agedependent changes of total testosterone, free testosterone, bioavailable testosterone, calculated free testosterone and SHBG in men aged 24-72 years.

Some authors reported positive associations between physical activity and androgen levels. An exercise-induced testosterone increase was found to be smaller in the elderly (Swerdloff and Wang 1993). Allen et al. (2002) reported that vigorous exercise lasting three or more hours per week was positively associated with testosterone and SHBG, but not with free testosterone. Muller et al. (2003) suggested that an increase in total testosterone, bioavailable testosterone and SHBG appears in the highly active group.

On the other hand, several studies did not reveal any associations between physical activity and androgens (Ponholzer et al. 2005, Svartberg et al. 2003, Ukkola et al. 2001, Shiels et al. 2009). We also reported a lack of association between androgen status and physical activity in men aged 45-58 years. There were no significant differences of total testosterone, free testosterone, dehydroepiandrosterone sulphate and estradiol concentrations between physically active (1.0-1.5 h of exercise twice a week, for about 10 years prior to the examination) and physically inactive middle-aged men (Medras et al. 2005).

It has also been suggested that low testosterone concentration reduces the level of physical activity (Van den Beld et al. 2000). An individually defined low level of androgens may be the cause of decreased physical activity.

\section{Conclusions}

Total testosterone, free testosterone, bioavailable testosterone, calculated free testosterone and estradiol decreases with age, inversely to the concentration of SHBG. The level of physical activity did not influence concentrations of androgens or SHBG. In younger, physically active males (24-48 years) serum estradiol was higher than in less active ones. On the contrary, older males (48-72 years) with higher level of physical activity had lower estradiol levels. Physical effort augmented estradiol decline with age. 


\section{Conflict of Interest}

There is no conflict of interest.

\section{Acknowledgements}

This work was supported by the Ministry of Science and Higher Education of Poland (grant code: 2PO5D 0730).

\section{References}

AIZAWA K, IEMITSU M, OTSUKI T, MAEDA S, MIYAUCHI T, MESAKI N: Sex differences in steroidogenesis in skeletal muscle following a single bout of exercise in rats. $J$ Appl Physiol 104: 67-74, 2008.

ALLEN NE, APPLEBY PN, DAVEY GK, KEY TJ: Lifestyle and nutritional determinants of bioavailable androgens and related hormones in British men. Cancer Causes Control 13: 353-363, 2002.

BIERNAT E, STUPNICKI R, LEBIEDZIŃSKI B, JANCZEWSKA L: Assessment of physical activity by applying IPAQ questionnaire. Phys Educ Sport 52: 83-89, 2008.

CONLEY A, HINSHELWOOD M: Mammalian aromatases. Reproduction 121: 685-695, 2001.

CRAIG CL, MARSHALL AL, SJOSTROM M, BAUMAN AE, BOOTH ML, AINSWORTH BE, BRATT M, EKELUND U, YNGVE A, SALLIS JF, OJA P: International physical activity questionnaire: 12-country reliability and validity. Med Sci Sports Exerc 35: 1381-1395, 2003.

DENTI L, PASOLINI G, SANFELICI L, BENEDETTI R, CECCHETTI A, CEDA GP, ABLONDI F, VALENTI G: Aging-related decline of gonadal function in healthy men: correlation with body composition and lipoproteins. Am Geriatr Soc 48: 51-58, 2000.

DRAFTA D, SCHINDLER AE, STROE E, NEACŞU E: Age-related changes of plasma steroids in normal adult males. J Steroid Biochem 17: 683-687, 1982.

FERRINI RL, BARRET-CONNOR E: Sex hormones and age: a cross-sectional study of testosterone and estradiol and their biovailable fractions in community dwelling men. Am J Epidemiol 147: 750-754, 1998.

FIELD AE, COLDITZ GA, WILLETT WC, LONGCOPE C, MCKINLAY JB: The relation of smoking, age, relative weight, and dietary intake to serum adrenal steroids, sex hormones, and sex hormone-binding globulin in middle-aged men. J Clin Endocrinol Metab 79: 1310-1316, 1994.

GRAY A, FELDMAN HA, MCKINLAY JB, LONGCOPE C: Age, disease, and changing sex hormone levels in middle-aged men: results of the Massachusetts Male Aging Study. J Clin Endocrinol Metab 73: 1016-1025, 1991.

KALETA D, MAKOWIEC-DABROWSKA T, JEGIER A: Occupational and leisure-time energy expenditure and body mass index. Int J Occup Med Environ Health 20: 9-16, 2007.

KAUFMAN JM, VERMEULEN A: The decline of androgen levels in elderly men and its clinical and therapeutic implications. Endocr Rev 26: 833-876, 2005.

KHOSLA S, MELTON LJ, ATKINSON EJ, O'FALLON WM, KLEE GG, RIGGS BL: Relationship of serum sex steroid levels and bone turnover markers with bone mineral density in men and women: a key role for bioavailable estrogen. J Clin Endocrinol Metab 83: 2266-2274, 1998.

LAPAUW B, GOEMAERE S, ZMIERCZAK H, VAN POTTELBERGH I, MAHMOUD A, TAES Y, DE BACQUER D, VANSTEELANDT S, KAUFMAN JM: The decline of serum testosterone levels in community-dwelling men over 70 years of age: descriptive data and predictors of longitudinal changes. Eur $J$ Endocrinol 159: 459-468, 2008.

MADDISON R, NI MHURCHU C, JIANG Y, VANDER HOORN S, RODGERS A, LAWES CM, RUSH E: International Physical Activity Questionnaire (IPAQ) and New Zealand Physical Activity Questionnaire (NZPAQ): a doubly labelled water validation. Int J Behav Nutr Phys Act 4: 62, 2007

MEDRAS M, SLOWINSKA-LISOWSKA M, JOZKOW P: Impact of recreational physical activity on bone mineral density in middle-aged men. Aging Male 8: 162-165, 2005.

MULLER M., TONKELAAR I, THIJSSEN J, GROBBEE D, SCHOUW YT: Endogenous sex hormones in men aged 40-80 year. Eur J Endocrinol 149: 583-589, 2003. 
PONHOLZER A, PLAS E, SCHATZL G, STRUHAL G, BRÖSSNER C, MOCK K, RAUCHENWALD M, MADERSBACHER S, SVARTBERG J, MIDTBY M, BØNAA KH, SUNDSFJORD J, JOAKIMSEN RM, JORDE R: Relationship between testosterone serum levels and lifestyle in aging men. Aging Male 8: 190-193, 2005.

RZEWNICKI R, VANDEN AUWEELE Y, DE BOURDEAUDHUIJ I: Addressing overreporting on the International Physical Activity Questionnaire(IPAQ) telephone survey with a population sample. Public Health Nutr 6: 299305, 2003.

SHIELS MS, ROHRMANN S, MENKE A, SELVIN E, CRESPO CJ, RIFAI N, DOBS A, FEINLEIB M, GUALLAR E, PLATZ EA: Association of cigarette smoking, alcohol consumption, and physical activity with sex steroid hormone levels in US men. Cancer Causes Control 20: 877-886, 2009.

SVARTBERG J, JORDE R: Endogenous testosterone levels and smoking in men. The fifth Tromsø study. Int J Androl 30: 137-143, 2007.

SVARTBERG J, MIDTBY M, BØNAA KH, SUNDSFJORD J, JOAKIMSEN RM, JORDE R: The associations of age, lifestyle factors and chronic disease with testosterone in men: the Tromsø Study. Eur J Endocrinol 149: 145$152,2003$.

SWERDLOFF RS, WANG C: Androgens and aging in men. Exp Gerontol 28: 435-446, 1993.

UKKOLA O, GAGNON J, RANKINEN T, THOMPSON PA, HONG Y, LEON AS, RAO DC, SKINNER JS, WILMORE JH, BOUCHARD C: Age, body mass index, race and other determinants of steroid hormone variability: the HERITAGE Family Study. Eur J Endocrinol 145: 1-9, 2001.

VAN DEN BELD A, HUHTANIEMI IT, PETTERSSON KS, POLS HA, GROBBEE DE, DE JONG FH, LAMBERTS SW: Luteinizing hormone and different genetic variants, as indicators of frailty in healthy elderly men. J Clin Endocrinol Metab 84: 1334-1339, 1999.

VAN DEN BELD AW, De JONG FH, GROBBEE DE, POLS HA, LAMBERTS SW: Measures of bioavailable serum testosterone and estradiol and their relationships with muscle strength, bone density, and body composition in elderly men. J Clin Endocrinol Metab 85: 3276-3282, 2000.

VANDERSCHUEREN D, VANDENPUT L: Androgens and osteoporosis. Andrologia 32: 125-130, 2000.

WOLIN KY, COLANGELO LA, LIU K, STERNFELD B, GAPSTUR SM: Associations of androgens with physical activity and fitness in young black and white men: the CARDIA Male Hormone Study. Prev Med 44: 426-431, 2007. 